\title{
Market-Based Coordination of Transmission and Generation Capacity Planning
}

\author{
Jae Hyung Roh, Mohammad Shahidehpour, Fellow, IEEE, and Yong Fu, Member, IEEE
}

\begin{abstract}
We propose an ISO model for coordinating transmission expansion planning with competitive generation capacity planning in electricity markets. The purpose of the model is a holistic simulation of generation and transmission capacity expansion in the market environment. The solution represents an iterative process for simulating the interactions among GENCOs, TRANSCOs, and the ISO, which might be terminated by the ISO based on a pre-specified stopping criterion. The proposed model adopts a joint energy and transmission auction market and a capacity mechanism. The joint auction market enables competition to occur among generation and transmission resources. The capacity mechanism offers incentives for market participant investments that reflect the locational values of additional capacity. Transmission capacity expansion decisions are made by merchant transmission lines that recover their capacity investments through transmission marginal pricing and capacity payments. Transmission network security is reflected in the proposed competitive resource planning model. The examples illustrate a coordinated planning of generation and transmission in restructured power systems.
\end{abstract}

Index Terms-Benders decomposition, competitive electricity markets, generation capacity planning, Lagrangian relaxation, merchant transmission, mixed integer programming, transmission network security, transmission planning.

\section{NOMENCLATURE}

\section{Indices:}

$b \quad$ Index for subperiod.

$C \quad$ Superscript index for candidate unit or line.

$E \quad$ Superscript index for existing unit or line.

$h \quad$ Index for GENCO.

$i \quad$ Index for generating unit.

$j \quad$ Index for transmission line.

$k \quad$ Index for flowgate.

$m \quad$ Starting node of transmission line $j$.

$n \quad$ Ending node of transmission line $j$.

$q \quad$ Index for TRANSCO.

$r \quad$ Superscript index of Benders iteration.

$t \quad$ Index for year.

$\wedge \quad$ Index for given variables.

Manuscript received October 18, 2006; revised August 7, 2007. Paper no. TPWRS-00723-2006.

The authors are with the Electrical and Computer Engineering Department, Illinois Institute of Technology, Chicago, IL 60616 USA (e-mail: rohjaeh@iit. edu; ms@iit.edu; fuyong@iit.edu).

Digital Object Identifier 10.1109/TPWRS.2007.907894

\section{Parameters:}

$C G_{h} \quad$ Number of candidate units of GENCO $h$.

$C L_{q} \quad$ Number of candidate lines of TRANSCO $q$.

$C F_{q} \quad$ Number of candidate flowgates of TRANSCO $q$ (two times the number of candidate transmission lines).

$D T_{b t} \quad$ Duration of subperiod $b$ in year $t$.

d Discount rate.

$E G_{h} \quad$ Number of existing generating units of GENCO $h$.

$F B I D_{k q b t} \quad$ Bid price of flowgate $k$ of TRANSCO $q$ at subperiod $b$ in year $t$.

$F G_{k q}^{\max } \quad$ Capacity of candidate flowgate $k$ of TRANSCO $q$.

$F I C_{j q t} \quad$ Investment cost of transmission line $j$ of TRANSCO $q$ in year $t$.

$F O_{k q b t} \quad$ Operating cost of flowgate $k$ of TRANSCO $q$ at subperiod $b$ in year $t$.

$N B I \quad$ Number of Benders iterations.

ND Number of buses.

NGC Number of GENCOs.

NTC Number of TRANSCOs.

NS Number of subperiods.

NT Number of planning years.

PBID $D_{i h b t} \quad$ Bid price of unit $i$ of GENCO $h$ at subperiod $b$ in year $t$.

$P I C_{i h t} \quad$ Investment cost of unit $i$ of GENCO $h$ in year $t$.

$P D_{m b t} \quad$ Load at bus $m$ at subperiod $b$ in year $t$.

$P O_{i h b t} \quad$ Operating cost of generating unit $i$ of GENCO $h$ at subperiod $b$ in year $t$.

$P_{i h}^{\max } \quad$ Capacity of generating unit $i$ of GENCO $h$.

$P L_{j q}^{\max } \quad$ Capacity of transmission line $j$ of TRANSCO $q$.

$S t^{+}, S t^{-} \quad$ Step size for Lagrangian multiplier update.

$\chi_{j q} \quad$ Reactance of transmission line $j$ of TRANSCO $q$.

$\theta_{\text {ref }} \quad$ Reference bus angle.

\section{Decision Variables:}

$F G_{k q b t} \quad$ Dispatched capacity of flowgate $k$ of $F P_{k q b t} \quad$ Flowgate Marginal Price for flowgate $k$ of TRANSCO $q$ at subperiod $b$ in year $t$. 


$\begin{array}{ll}P G_{i h b t} & \begin{array}{l}\text { Dispatched capacity of generating unit } i \text { of } \\ \text { GENCO } h \text { at subperiod } b \text { in year } t .\end{array} \\ P L_{j q b t} & \begin{array}{l}\text { Flow on line } j \text { of TRANSCO } q \text { at subperiod } b \\ \text { in year } t .\end{array} \\ P P_{i h b t} & \begin{array}{l}\text { Locational Marginal Price for unit } i \text { of } \\ \text { GENCO } h \text { at subperiod } b \text { in year } t .\end{array} \\ X_{i h t} & \text { Installation status of candidate unit } i \text { of } \\ & \text { GENCO } h \text { in year } t, 1 \text { if installed, otherwise } \\ Y_{j q t} & \text { o. } \\ & \begin{array}{l}\text { Installation status of transmission line } j \\ \text { of TRANSCO } q \text { in year } t, 1 \text { if installed, }\end{array} \\ & \text { otherwise } 0 . \\ \lambda, \pi, \rho, \mu, & \text { Bus angle. } \\ \varphi, \gamma & \text { Lagrangian multipliers. } \\ \alpha_{i h b t} & \text { Capacity signal for unit } i \text { of GENCO } h \text { at } \\ \beta_{j q b t} & \text { subperiod } b \text { in year } t . \\ & \text { Capacity signal for line } j \text { of TRANSCO } q \text { at } \\ & \text { subperiod } b \text { in year } t .\end{array}$

Matrices and Vectors:

$\begin{array}{ll}\mathbf{A} & \text { Bus-unit incidence matrix. } \\ \mathbf{B} & \text { Bus-load incidence matrix. } \\ \mathbf{K} & \text { Bus-branch incidence matrix. } \\ \mathbf{P} & \text { Real power output vector. } \\ \mathbf{P T D F} & \text { Power distribution factor matrix. } \\ \mathbf{P}_{\mathbf{D}} & \text { Load vector. } \\ \mathbf{S}_{\mathbf{1}}, \mathbf{S}_{\mathbf{2}} & \text { Slack variable vectors. } \\ \mathbf{P L} & \text { Real power flow vector. } \\ \mathbf{X} & \text { Installation status vector consists of } X_{i h t} . \\ \mathbf{Y} & \text { Installation status vector consists of } Y_{j q t} . \\ \mathbf{F G} & \text { Dispatched flowgate vector consist of } \\ \mathbf{F G} & F G_{k q b t}^{C} \text {. } \\ \mathbf{1} & \text { Existing flowgate capacity vector. }\end{array}$

\section{INTRODUCTION}

$\mathbf{R}$ ECENT events in the United States and Europe proved that the net social costs of under-investment in transmission could exceed the cost of overinvestment due to substantial increases in consumer costs incurred from even minute transmission capacity shortages [1], [2]. There are various obstacles to transmission planning in a competitive market. It is appealing to build enough transmission so that it would never constrain generation markets. However, the reality is that the construction of new transmission lines is often opposed by local residents and landowners and is therefore politically difficult to achieve. In addition, regulatory rules may not permit utilities to recover fully the cost of such overbuilt systems. Furthermore, transmission plans based on market forces could neglect the public value of providing adequate reliability. In principle, agreement among planners is growing that some form of market-based planning coupled with physical constraints, regulatory perspectives, and public interests is essential in the long term. Such market-based approaches will provide signals to investors on where to locate new generation and will help system planners, regulators, and local authorities decide and agree on transmission planning and siting [1].

In electricity market designs, transmission asset owners have been represented as passive market participants. Recent market design proposals and policies suggest that transmission owners ought to be active participants and incentives should be provided for transmission capacity investments [3]. This paper presents a market-based model for the coordination of long-term resource (i.e., generation and transmission) planning process. The proposed model is characterized by a joint energy and transmission auction market and a capacity mechanism. The market-based resource planning provides locational signals to market participants for coordinating investments on transmission and generation resources. We demonstrate that merchant transmission and its profit maximization as dispatchable flowgates could play a major role in transmission capacity expansion.

A dispatchable flowgate is a transmission capacity for which bids are submitted to the market [4] and [5]. The merchant transmission is assumed to recover its investments through flowgate marginal prices determined by the joint energy and transmission auction market and capacity payments provided by a capacity mechanism defined in Section II. In contrast, under the FERC's proposed SMD, a transmission investor is granted fixed transmission rights (FTRs) as the financial value of the difference (spread) between day-ahead market prices at the two ends of a new transmission line [6].

There is a general consensus that generation capacity expansion can be driven by prices and that the same principle may not apply to transmission capacity expansion. Nevertheless, with the introduction of merchant transmission to electricity markets, it is possible to have a competitive process for maximizing transmission revenues. The merchant transmission could stimulate a competitive market for transmission capacity expansion because if an incumbent transmission company does not plan to expand its capacity in the market, another market participating company would [7].

The generation capacity market and the institution of capacity signals have been a controversial issue in electricity industry restructuring. Many experts argue that the capacity mechanism is essential for encouraging investments in new capacity [8]. In theory, energy and ancillary services markets should provide incentives for additional investments in electricity supply. However, most peaking units may not recover their fixed costs of investment without market price spikes. Thus, significant price volatility may be necessary to make such investments feasible in the absence of capacity payments [9]. Given the political realities of electricity markets, prices may fluctuate insufficiently to induce investment when available capacity is tightened; then an explicit capacity mechanism would be needed to signal capacity shortages and induce investments on electricity supply. Our proposed model is based on such an argument for capacity mechanisms that will supplement market participant revenues in competitive electricity markets. The capacity revenue allows regulators to set prices at politically 
acceptable levels and yet motivate market participants to make individual investment decisions.

In electricity markets, the regulatory body, or ISO, is responsible for the security of system operations. The responsibility would include the coordination between capacity expansion and transmission network security. The ISO's role in resource planning is assumed to be limited to ensuring that capacity expansion plans do not cause excessive transmission congestion or endanger the system reliability. In this paper, the ISO is assumed to provide capacity signals as well as energy and flowgate price signals.

Previous technical publications addressed a number of approaches for solving the generation planning problem in a competitive market environment. Reference [10] presented a generation planning process involving decisions on new plant construction by applying the Cournot model at a single point in time. It assumed that the information on other generator expansion plans was available for each player. Reference [11] proposed a detailed two-stage model of investment in generation capacity in restructured power systems. In the two-stage game, generation investment decisions were made at the first stage while spot market operations were managed at the second stage. Reference [12] used stochastic dynamic programming to identify an optimal investment strategy for one investor when the objective was to maximize the investor's expected profit. It assumed that the average electricity price over the year was a function of the ratio of average load to average available capacity and there was a functional relationship between the average price and the spot price volatility. Reference [13] applied an agent-based model for generation expansion. The generation planning model in our paper differs from previous models as our model is embedded in an interactive framework in which the transmission investor is also included in decision making. The locational capacity payment is also defined in our paper and used as an incentive for generator investment.

There have been other proposed approaches based on the Benders decomposition method for solving the generation or transmission planning problem in a competitive market environment. Reference [14] applied Benders decomposition for distributed utility planning. It modeled distributed resources and local distribution reinforcement as integer variables while representing transmission and central generation options as continuous variables. Reference [15] applied a Benders decomposition approach to solve transmission expansion planning problems without considering generation expansions. However, the feasibility cannot be imposed by adding coupling constraints (Benders cuts) to the investment problem of each player in a market environment because there are, in a sense, multiple master problems. In our model, financial incentives are provided by the ISO to generators by applying the Lagrangian relaxation to the cuts.

Recently, [16] made a study on the interaction between transmission and generation in transmission planning. It characterized a transmission planning process whose objective was to maximize social welfare based on a valuation methodology outlined as proactive network planning. The approach in [16] did not attempt to solve the transmission planning problem; rather it used the formulation as a framework for evaluating alternative predetermined transmission expansion proposals. In [16], a network planner was assumed to be the Stackelberg leader that anticipated the way generation investment and operations would react. In contrast, our model assumes that the transmission and generator investors do not anticipate each other's reactions.

In this paper, we do not propose a typical optimization or market equilibrium model. Our heuristic market-based simulation model incorporates the desirable features of locational signals for investment, individual decisions by autonomous market players, and holistic simulations of transmission and generation in long term resource planning. In addition, our model reflects the limited information shared among market players, which is an important feature in the modeling of a market environment. The proposed simulations present and coordinate the decisionmaking behavior of individual market players. However, the applicability of our model to current electricity markets could be complicated as our model adopts the concept of merchant TRANSCOs reimbursed by flowgate payments and a capacity payment mechanism, which is a departure from prevailing US electricity markets. Another potential difficulty is that our iterative scheme may not converge every time. Accordingly, the ISO may stop the coordination process and make a final decision based on pre-specified market rules.

The rest of the paper is organized as follows. Section II describes the proposed model. Section III provides formulation of problems and solution methodology in detail. Section IV presents and discusses the case studies of a two-bus system and a 30-bus system over 10 year planning period. The conclusion drawn from the study is provided in Section V.

\section{MODEL DESCRIPTION}

Fig. 1 sketches the proposed market-based model. At first, GENCOs and TRANSCOs provide capacity investment decisions to the ISO for approval. GENCOs' and TRANSCOs' investment decisions would be based on individual profit maximization while considering their respective constraints. The ISO aggregates resource planning proposals and checks the security of transmission network. The network security is interpreted as a system wide constraint. If the transmission network security is not met, the ISO provides GENCOs and TRANSCOs with capacity signals that represent the added value of generating units or transmission capacity for security. If the transmission network security is met, the ISO calculates locational marginal prices (LMPs) and flowgate marginal prices (FMPs) based on the proposed investment plan. Accordingly, the projected price signals are provided by the ISO to GENCOs and TRANSCOs for capacity investment planning. The revised optimal transmission and generation capacity planning decisions are submitted iteratively by GENCOs and TRANSCOs to the ISO and the iterative process will continue until a solution is reached for satisfying the stopping criterion. If a cycling pattern emerges during the solution process, the ISO may stop the coordination process and make a final decision based on pre-specified market rules. In our model, the ISO is assumed not to determine the required capacity as in the current US capacity market. Instead, the ISO provides market players with a certain capacity signal based on security criteria (rather than a reserve margin requirement) and 


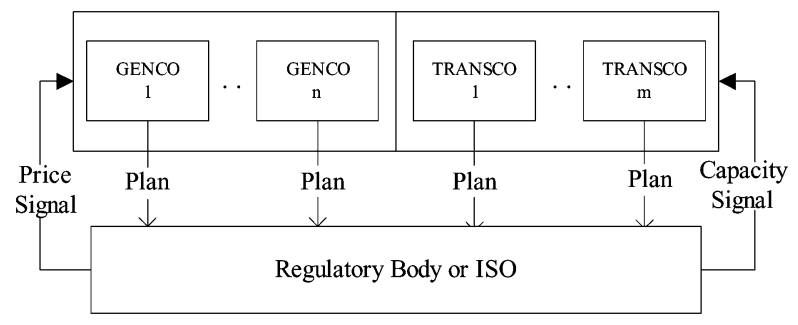

Fig. 1. Resource planning framework.

receives their market responses. Through this iterative process, the ISO will determine capacity payments. Although it is not a feature of current US markets, the algorithm proposes a general planning model that can incorporate generation and transmission planning in the market environment by using market-based signals such as LMPs, FMPs, and locational capacity payments. It is assumed that the capacity payment would be contractually binding between the ISO and market players, i.e., GENCOs and TRANSCOs, while the projected energy prices are not binding.

To reflect the ISO's transmission network security assessment in a multi-GENCO and merchant TRANSCO investment decisions, capacity signals are introduced as incentives for adding generating units and transmission capacities. The algorithm for calculating such signals utilizes Benders decomposition [17]-[19] and Lagrangian relaxation. Unlike the general Benders decomposition approach [20], [21], a single master problem is not defined in our model because the individual's profit maximization is considered separately for each market player in the Benders master problem. The proposed decomposition will then determine security cuts which guarantee the feasibility of the master problem. The MIP method is not suitable for solving the master problem because the cuts are coupling constraints among all market players. Accordingly, the relaxation technique is used for dealing with the optimization problem for individual players at the Benders master problem level. The Lagrangian multipliers act as market incentives to provide sufficient capacity so that security constraints are met.

At the Benders master problem level, profit maximization problems are solved for GENCOs and TRANSCOs. The ISO's security check problem is regarded as Benders subproblem. The Benders cuts, created when the security constraints are not met with the proposed investment plans, represent coupling constraints which are system-wide constraints for security. The Lagrangian relaxation algorithm is applied to relax complicated and linking constraints into the objective function of planning problems and obtain locational capacity signals [22]. The detailed formulation will be discussed in Section III.

The ISO would compensate GENCOs and TRANSCOs based on capacity signals for maintaining the system security. Accordingly, GENCOs obtain their revenues from capacity and energy payments and TRANSCOs obtain their revenues from capacity and flowgate payments. The energy payments for GENCOs are simulated by LMPs, which are calculated by the ISO and introduced into GENCOs' capacity investment decisions. The FMP is also calculated and provided by the ISO to facilitate TRANSCOs' capacity investment decisions. The LMP is the marginal cost of supplying the next increment

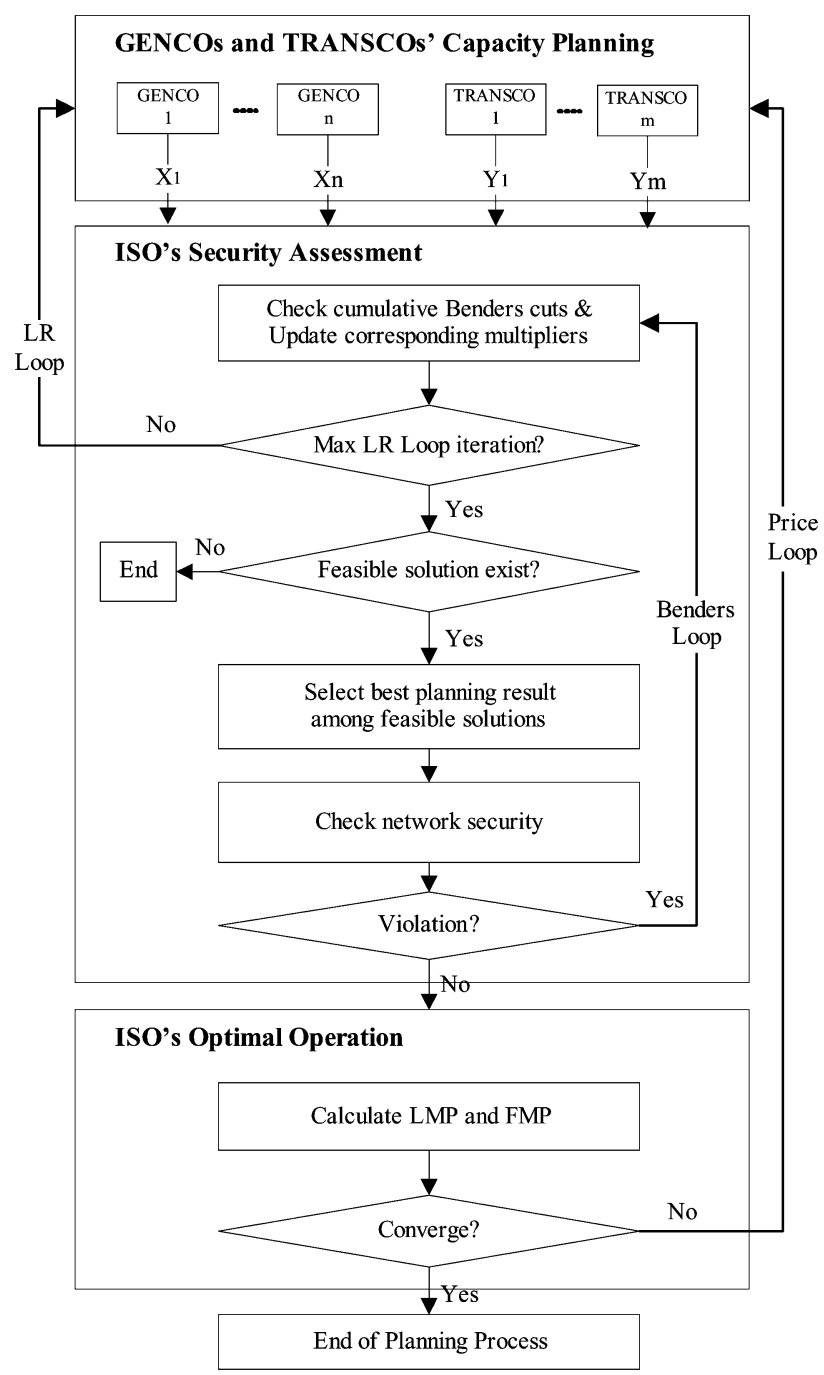

Fig. 2. Decomposition and coordination for capacity planning.

of electric energy at a specific bus considering the generation marginal cost and the physical aspects of the transmission system. Similarly, the FMP is the shadow price associated with a flowgate. The FMP is equivalent to a change in social benefit of transaction settled through the spot market when transmission constraint is relaxed by an increment [4]. LMPs and FMPs are calculated in this paper by a joint auction of energy and transmission capacity.

\section{Problem Formulation and Solution Methodology}

The proposed capacity planning model simulates the decision-making behavior of individual market players while satisfying planning and operation constraints. The constraints are summarized as follows.

- Planning Constraints: Proposed sites and capacity for generating units and transmission lines.

- Operation Constraints: Power balance, generation and transmission capacity limits, etc.

The security-constrained planning problem consists of three problems shown in Fig. 2. Those problems include GENCO's and TRANSCO's capacity planning problem, the ISO's transmission network security check problem, and the ISO's optimal 
operation problem. The solution steps for the proposed capacity planning process given in Fig. 2 are as follows.

Step 1) Individual GENCOs' generation capacity planning problem and TRANSCOs' merchant transmission capacity planning problem are solved based on initially forecasted LMPs and FMPs. Each GENCO and TRANSCO maximizes its profit according to locational price signals by calculating capacity planning decision variables $\mathbf{X}$ and $\mathbf{Y}$.

Step 2) Benders Loop-According to the submitted $\mathbf{X}$ and $\mathbf{Y}$ values, the ISO checks the transmission network security by minimizing nodal power balance violations. The transmission network security check is a continuous optimization problem when variables $\mathbf{X}$ and $\mathbf{Y}$ are fixed. Once a nodal power balance violation is detected, corresponding Benders cuts are generated and returned to the capacity planning problem of GENCOs and TRANSCOs via Lagrange multipliers in Step 3. If there is no violation, we proceed to Step 4.

Step 3) LR Loop-Lagrangian relaxation is applied to solve the capacity planning problem with Benders cuts as coupling constraints. Depending on the capacity planning solution for satisfying Benders cuts, Lagrangian multiplier $\pi$ is updated and capacity signals are formed by the ISO and fed back to individual GENCOs and TRANSCOs for recalculating $\mathbf{X}$ and $\mathbf{Y}$. In each iteration, corresponding capacity signals are provided to GENCOs and TRANSCOs which make their own investment decisions based on capacity signals. We may identify several alternative feasible investment solutions that satisfy the Benders cuts after a given number of Lagrangian relaxation iterations. For each feasible solution, we calculate the capacity payment that the ISO would pay to GENCOs and TRANSCOs over the planning period. Among these feasible solutions, the one with the minimum capacity payment will be selected by the ISO as the best solution. One of the ISO's functions is to maintain security at minimum cost. An excessive capacity payment (i.e., capacity signal multiplied by the installed capacity) may result in a higher social cost (i.e., sum of investment cost and production costs based on accepted bids). Thus, the strategy for selecting the minimum capacity payment is considered at the ISO's security assessment stage. The capacity planning problem will be declared infeasible if no feasible solution is found.

Step 4) Price Loop-The ISO solves the optimal operation problem and calculates LMPs and FMPs for the given $\mathbf{X}$ and $\mathbf{Y}$ in Step 3. The optimal operation is a continuous problem with the objective of maximizing the social surplus. The LMPs and FMPs are fed back to GENCOs and TRANSCOs iteratively until the convergence criterion is met.

We consider a capacity planning period which could be as long as two decades. Within this period, some of the new facilities may come onboard quicker while the others would require a longer lead time for construction. Typically, building a new transmission facility, including licensing, may take an extended period of 5-10 years [23]. The construction of a large thermal unit may also take 3-9 years. However, the installation of small distributed generation could take less than 2 years [24]. The algorithm will select the year of construction for the proposed facilities in order to simulate the operation of the market. A planning year is divided into multiple subperiods with fixed loads. The number of subperiods could vary depending on planning requirements and load patterns. For example, we could use 4 subperiods to represent seasonal loads or 12 subperiods for monthly loads. Mixed integer programming is used for GENCOs' and TRANSCOs' capacity planning problem. Linear programming is applied to the ISO's security check problem and operation problem [25]. The problem formulations are discussed as follows.

\section{A. Gencos' Generation Capacity Planning}

Generation capacity planning has historically addressed the problem of identifying generating unit type, size, siting, and timing for adding new generating capacity economically and in a manner that ensures that the installed capacity would adequately meet the projected demand growth. In competitive markets, the main objective of a GENCO's investment planning is to maximize profit. Accordingly, the objective function of generation capacity planning problem is to maximize GENCOs' profit over the planning horizon. The GENCO $h$ 's capacity investment planning problem is formulated as follows:

$$
\begin{aligned}
& \operatorname{Max} \sum_{t=1}^{N T} \sum_{b=1}^{N S} \sum_{i=1}^{E G_{h}} \frac{D T_{b t} *\left(P P_{i h b t}^{E}-P O_{i h b t}^{E}\right) * P G_{i h b t}^{E}}{(1+d)^{(t-1)}} \\
&+\sum_{t=1}^{N T} \sum_{b=1}^{N S} \sum_{i=1}^{C G_{h}} \frac{D T_{b t} *\left(P P_{i h b t}^{C}-P O_{i h b t}^{C}\right) * P G_{i h b t}^{C}}{(1+d)^{(t-1)}} \\
&-\sum_{t=1}^{N T} \sum_{i=1}^{C G_{h}} \frac{\left(P I C_{i h t} * X_{i h t}\right)}{(1+d)^{(t-1)}} \\
&+\sum_{t=1}^{N T} \sum_{b=1}^{N S} \sum_{i=1}^{C G_{h}} \frac{D T_{b t} *\left(\alpha_{i h b t} * X_{i h t}\right)}{(1+d)^{(t-1)}} \\
& \text { S.t. } 0 \leq P G_{i h b t}^{E} \leq P G_{i h}^{E, \max } \quad \forall i, \quad \forall b, \quad \forall t \\
& 0 \leq P G_{i h b t}^{C} \leq P G_{i h}^{C, \max } * X_{i h t} \quad \forall i, \quad \forall b, \quad \forall t \\
& X_{i h t} \leq X_{i h(t+1)} \quad \forall i, \forall t .
\end{aligned}
$$

The first two terms in the objective function (1) are the difference between revenue and operating costs of existing and new generating units, respectively. The third term represents the capacity investment cost for new generating units. The fourth term represents the capacity payment that a generation unit could receive from the ISO for its contribution to security. The derivation of capacity payment is presented in Sections III-C-D. A GENCO can earn revenue from energy and capacity payments. The sum of the revenues minus operating costs and investment costs (only for new generating units) forms a GENCO's profit over the planning horizon. The decision variables are $P G_{i h b t}^{E}$, $P G_{i h b t}^{C}$ and $X_{i h t}$. However, only $X_{i h t}$ is submitted to the ISO. The types and capacity of generation alternatives are limited by location, technology, national policies, etc. In this paper, the generation capacity planning is assumed to be limited by the following constraints:

- unit technical characteristics such as capacity (2) and (3); 
- availability of sites for adding generating units; and

- types of generating units added at each candidate site.

Constraint (4) maintains the installation status of a generating unit. Every GENCO is operated independently for maximizing profit. As such, there is no coupling constraint among GENCOs and the investment problem is decomposed into several mixed-integer programs. A GENCO evaluates the value of its investment and profit based on its net present value. The higher the discount rate, the less profitable capital-intensive generating units will be. For simulation purposes, we assume a single discount rate for all GENCOs.

\section{B. Transcos' Transmission Capacity Planning}

We consider a candidate transmission line as a dispatchable capacity when TRANSCOs submit utilization bids for such transmission lines to the market. In other words, a merchant TRANSCO would bid flowgate capacities at positive prices [26]. Existing regulated transmission lines are assumed to be compensated based on the rate-base system and not considered in the investment objective function. A merchant TRANSCO's objective is to maximize profit, which is similar to that of GENCOs. The profit of a TRANSCO is determined by the market price of new transmission capacity, the MW dispatched capacity, operating costs, and investment costs. Transmission line capacity expansion is categorized into standard capacity blocks. Similar to generation planning, the transmission line capacity planning is assumed to be limited by available options. The TRANSCO $q$ 's investment problem is formulated as follows:

$$
\begin{aligned}
\operatorname{Max} & \sum_{t=1}^{N T} \sum_{b=1}^{N S} \sum_{k=1}^{C F_{q}} \frac{D T_{b t} *\left(F P_{k q b t}^{C}-F O_{k q b t}^{C}\right) * F G_{k q b t}^{C}}{(1+d)^{(t-1)}} \\
& -\sum_{t=1}^{N T} \sum_{j=1}^{C L_{q}} \frac{\left(F I C_{j q t} * Y_{j q t}\right)}{(1+d)^{(t-1)}} \\
& +\sum_{t=1}^{N T} \sum_{b=1}^{N S} \sum_{j=1}^{C L_{q}} \frac{D T_{b t} *\left(\beta_{j q b t} * Y_{j q t}\right)}{(1+d)^{(t-1)}} \\
\text { S.t } 0 \leq & F G_{k q b t}^{C} \leq F G_{k q}^{C, \max } * Y_{j q t} \\
0 \leq & F G_{(k+1) q b t}^{C} \leq F G_{(k+1) q}^{C, \max } * Y_{j q t} \\
& \forall j, \quad \forall t, k=2 * j-1 \\
Y_{j q t} & \leq Y_{j q(t+1)} \quad \forall j, \quad \forall t
\end{aligned}
$$

where the objective is to maximize TRANSCO's profit. The first term in the objective function (5) is the difference between revenue and operating costs. A TRANSCO's revenue is calculated based on FMPs and MW dispatched capacity of flowgates. The decision variables in this problem are $F G_{k q b t}^{C}$ and $Y_{j q t}$. The second term of the objective function (5) represents the investment costs for new lines. The third term is the additional capacity payment revenue. Following the ISO's security check, TRANSCOs may earn additional revenues through transmission capacity payments, which will be addressed in Section III-D. The TRANSCO's profit is calculated by subtracting operation and investment costs from its revenue. The set of planning constraints includes

- candidate flowgate capacity (6);
- availability of sites for adding transmission lines.

As each transmission line has flowgates in both directions, the installation status of a candidate transmission line defines the corresponding flowgates capacity limit as in (6). Constraint (7) maintains the installation status of a transmission line.

\section{ISO's Security Assessment}

The objective in the security check subproblem is to minimize real power mismatch at each bus. The purpose is to calculate capacity signals for constructing new generating units and transmission lines when existing generation and transmission capacity cannot satisfy the bus load balance. Once the candidate generating unit installation status $X_{i h t}$ and the candidate transmission line installation status $Y_{j q t}$ are calculated by participants and fixed by the ISO, nonnegative slack variables $\mathbf{S}_{\mathbf{1}}$ and $\mathbf{S}_{2}$ are added to the bus power balance constraint. The security check subproblem at subperiod $b$, year $t$, and Benders iteration $r$ is formulated as follows:

$$
\begin{aligned}
& \operatorname{Min} W^{r}=\mathbf{1}^{\mathbf{T}} * \mathbf{S}_{\mathbf{1}}+\mathbf{1}^{\mathbf{T}} * \mathbf{S}_{\mathbf{2}} \\
& \text { S.t. } \mathbf{K} * \mathbf{P L}+\mathbf{S}_{\mathbf{1}}-\mathbf{S}_{\mathbf{2}}=\mathbf{A} * \mathbf{P}-\mathbf{B} * \mathbf{P}_{\mathbf{D}} \\
& P L_{j q b t}^{E}=\frac{\left(\theta_{j q m b t}^{E}-\theta_{j q n b t}^{E}\right)}{\chi_{j q}^{E}} \quad \forall q, \forall j \\
& \left|P L_{j q b t}^{C}-\frac{\left(\theta_{j q m b t}^{C}-\theta_{j q n b t}^{C}\right)}{\chi_{j q}^{C}}\right| \\
& \leq M *\left(1-\hat{Y}_{j q t}\right) \quad \forall q, \forall j\left(\bar{\varphi}_{j q b t}^{r}, \underline{\varphi}_{j q b t}^{r}\right) \\
& \left|P L_{j q b t}^{E}\right| \leq P L_{j q}^{E, \max } \quad \forall q, \forall j \\
& \left|P L_{j q b t}^{C}\right| \leq P L_{j q}^{C, \max } * \hat{Y}_{j q t} \quad \forall q, \forall j\left(\bar{\gamma}_{j q b t}^{r}, \underline{\gamma}_{j q b t}^{r}\right) \\
& 0 \leq P G_{i h b t}^{E} \leq P G_{i h}^{E, \max } \quad \forall h, \forall i \\
& 0 \leq P G_{i h b t}^{C} \leq P G_{i h}^{C, \max } * \hat{X}_{i h t} \quad \forall h, \forall i\left(\lambda_{i h b t}^{r}\right) \\
& \theta_{\text {ref }}=0 .
\end{aligned}
$$

Here, the decision variables are $\mathbf{P}, \mathbf{S}_{\mathbf{1}}, \mathbf{S}_{\mathbf{2}}$, and $\theta$. The constraints are the first Kirchhoff's law for nodal power balance (9), the second Kirchhoff's law for transmission lines (10) and (11), transmission flow limits (12) and (13), generation capacity limits (14) and (15), and the angle of reference bus (16). $M$ in (11) is a large value to relax the equality constraint of candidate transmission line when $\hat{Y}_{j q t}$ is 0 . As suggested in [15], numerical tests should be performed for determining the empirical value of $M$ which could improve the approach.

The objective function (8) is to minimize real power mismatch. The ISO checks the transmission network security by adding slack variables $\mathbf{S}_{\mathbf{1}}$ and $\mathbf{S}_{\mathbf{2}}$ to the bus power balance constraint.

The proposed model considers normal state of operation in the feasibility check problem. However, contingency analyses could also be considered for enhancing the transmission and generation planning. In this subproblem, the adjustment of control variables including generation dispatch could minimize violations. A Benders cut at iteration $r(17)$ is generated and added to the GENCOs and TRANSCOs capacity planning problem when the objective function (8) is larger than zero. The Benders 
cut indicates that GENCOs and TRANSCOs could mitigate violations by readjusting the capacity investment plan in year $t$. If $W^{r}$ is larger than 0 , the Benders cut will be generated [22] as $W^{r}$

$$
\begin{aligned}
& +\sum_{q=1}^{N T C} \sum_{j=1}^{C L_{q}}\left[\begin{array}{c}
\left(\bar{\gamma}_{j q b t}^{r}+\underline{\gamma}_{j q b t}^{r}\right) * P L_{j q}^{C, \max } *\left(Y_{j q t}-\hat{Y}_{j q t}\right) \\
-\left(\bar{\varphi}_{j q b t}^{r}+\underline{\varphi}_{j q b t}^{r}\right) * M *\left(Y_{j q t}-\hat{Y}_{j q t}\right)
\end{array}\right] \\
& +\sum_{h=1}^{N G C} \sum_{i=1}^{C G_{h}}\left[\lambda_{i h b t}^{r} * P G_{i h}^{C, \max } *\left(X_{i h t}-\hat{X}_{i h t}\right)\right] \leq 0
\end{aligned}
$$

After combining corresponding coefficients for each variable and transferring the constant term to the right-hand side of (17), the Benders cut is given as

$$
\sum_{h=1}^{N G C} \sum_{i=1}^{C G_{h}}\left(\psi_{i h b t}^{r} * X_{i h t}\right)+\sum_{q=1}^{N T C} \sum_{j=1}^{C L_{q}}\left(\zeta_{j q b t}^{r} * Y_{j q t}\right) \leq \hat{e}_{b t}^{r}
$$

where

$$
\begin{aligned}
& \psi_{i h b t}^{r}=\lambda_{i h b t}^{r} * P G_{i h}^{C, \max } \\
& \zeta_{j q b t}^{r}=\left(\bar{\gamma}_{j q b t}^{r}+\underline{\gamma}_{j q b t}^{r}\right) * P L_{j q}^{C, \max }-\left(\bar{\varphi}_{j q b t}^{r}+\underline{\varphi}_{j q b t}^{r}\right) * M \\
& \hat{e}_{b t}^{r}=-W^{r}+\sum_{h=1}^{N G C} \sum_{i=1}^{C G_{h}}\left[\lambda_{i h b t}^{r} * P G_{i h}^{C, \max } * \hat{X}_{i h t}^{r}\right] \\
& +\sum_{q=1}^{N T C} \sum_{j=1}^{C L_{q}}\left[\begin{array}{c}
\left(\bar{\gamma}_{j q b t}^{r}+\underline{\gamma}_{j q b t}^{r}\right) * P L_{j q}^{C, \max } * \hat{Y}_{j q t} \\
-\left(\bar{\varphi}_{j q b t}^{r}+\underline{\varphi}_{j q b t}^{r}\right) * M * \hat{Y}_{j q t}
\end{array}\right] .
\end{aligned}
$$

Here, the multiplier $\psi_{i h b t}^{r}$ is interpreted as the decrement of violations with respect to $X_{i h t}$. Similarly, $\zeta_{j q b t}^{r}$ is interpreted as the decrement of violation with respect to $Y_{j q t}$.

\section{Relaxation of Benders Cuts}

Using Benders decomposition, the coupling of GENCOs and TRANSCOs is represented by cuts (18). Then, Lagrangian relaxation is applied to relax the coupling constraints into the individual objective function of GENCOs and TRANSCOs. The subgradient method is applied to update Lagrangian multipliers [27]. Based on given decision variables $\hat{X}_{i h t}$ and $\hat{Y}_{j q t}$, the ISO checks Benders cuts and updates the corresponding non-positive multiplier $\pi$ as follows:

If

$$
\begin{gathered}
\sum_{h=1}^{N G C} \sum_{i=1}^{C G_{h}}\left(\psi_{i h b t}^{r} * \hat{X}_{i h t}\right)+\sum_{q=1}^{N T C} \sum_{k=1}^{C L_{q}}\left(\zeta_{j q b t}^{r} * \hat{Y}_{j q t}\right) \leq \hat{e}_{b t}^{r} \\
\pi_{b t}^{\text {new }, r}=\pi_{b t}^{\text {old }, r}-S t^{-} *\left[\begin{array}{c}
\sum_{h=1}^{N G C} \sum_{i=1}^{C G_{h}}\left(\psi_{i h b t}^{r} * \hat{X}_{i h t}\right)+ \\
\sum_{q=1}^{N T C C L_{q}} \sum_{k=1}^{r}\left(\zeta_{j q b t}^{r} * \hat{Y}_{j q t}\right)-\hat{e}_{b t}^{r}
\end{array}\right]
\end{gathered}
$$

otherwise

$$
\pi_{b t}^{\text {new }, r}=\pi_{b t}^{\text {old }, r}-S t^{+} *\left[\begin{array}{c}
\sum_{h=1}^{N G C} \sum_{i=1}^{C G_{h}}\left(\psi_{i h b t}^{r} * \hat{X}_{i h t}\right)+ \\
\sum_{q=1}^{N T C C L_{q}} \sum_{k=1}^{r}\left(\zeta_{j q b t}^{r} * \hat{Y}_{j q t}\right)-\hat{e}_{b t}^{r}
\end{array}\right]
$$

where $S t^{+}$and $S t^{-}$are step sizes for updating multipliers $\pi$. The subgradient method provides a simple iterative solution with a small computation cost for the Lagrangian dual problem. The prefixed step size is used to modify the corresponding Lagrangian multipliers. Initially, the convergence speed is high, which will slow down as the number of iterations increases with a near-optimal solution. Although the subgradient method may oscillate at final iterations, it is still an efficient method for solving the Lagrangian dual problem [29]. We could improve the convergence of subgradient method by introducing adaptive steps at final iterations or adaptive methods for adjusting Lagrangian multipliers. Accordingly, Lagrangian multipliers have to be adjusted skillfully. Once Benders cuts are relaxed and introduced into the capacity planning problem via Lagrangian multiplier $\pi$, the capacity signals $\alpha_{i h b t}$ and $\beta_{j q b t}$ that are introduced to the objective functions of profit maximization problems for GENCOs and TRANSCOs are calculated as follows:

$$
\begin{aligned}
\alpha_{i h b t} & =\sum_{r=1}^{N B I}\left(\pi_{b t}^{r} * \psi_{i h b t}^{r}\right) \\
\beta_{j q b t} & =\sum_{r=1}^{N B I}\left(\pi_{b t}^{r} * \zeta_{j q b t}^{r}\right) .
\end{aligned}
$$

Note that $\alpha_{i h b t}$ for a new generating unit $i$ and $\beta_{j q b t}$ for a new transmission line $j$ at subperiod $b$ in year $t$ are interpreted as capacity signal for adding the corresponding component. $\alpha_{j q b t}$ and $\beta_{j q b t}$ are incentives paid to GENCOs and TRANSCOs by the ISO for system security. The ISO could recover funds for capacity signals from consumers through various methods such as in proportion to consumption. However, this issue will be discussed in subsequent papers as this paper concentrates on calculating economic signals for security in capacity planning. If load shedding is considerably diminished after a generating unit or a transmission line is added, then $\alpha_{i h b t}$ and $\beta_{j q b t}$ should be high.

\section{E. ISO's Optimal Operation Subproblem}

In this subproblem, we calculate bus LMPs, FMPs, and accepted generation and transmission bid quantities. The objective of auction in the optimal operation subproblem is to maximize the revealed surplus based on submitted bids for generation, demand, and incremental transmission. The revealed surplus is defined as the difference between consumption payments based on accepted bids and production costs. When the demand is assumed to be inelastic and always satisfied, the objective function will be to minimize the system as-bid cost for the given $\hat{X}_{i h t}$ and 
$\hat{Y}_{j q t}$. The optimal operation subproblem in year $t$ and subperiod $b$ is formulated as follows:

$$
\begin{aligned}
& \operatorname{Min} \sum_{h=1}^{N G C} \sum_{i=1}^{E G_{h}} P B I D_{i h b t}^{E} * P G_{i h b t}^{E} \\
& +\sum_{h=1}^{N G C} \sum_{i=1}^{C G_{h}} P B I D_{i h b t}^{C} * P G_{i h b t}^{C} \\
& +\sum_{q=1}^{N T C} \sum_{k=1}^{C F_{q}}\left(F B I D_{k q b t}^{C} * F G_{k q b t}^{C}\right) \\
& \text { S.t. } \sum_{h=1}^{N G C} \sum_{i=1}^{E G_{h}} P G_{i h b t}^{E}+\sum_{h=1}^{N G C} \sum_{i=1}^{C G_{h}} P G_{i h b t}^{C} \\
& =\sum_{m=1}^{N D} P D_{m b t} \rho_{b t} \\
& \mathbf{P T D F}_{\mathbf{E}} *\left(\mathbf{A} * \mathbf{P}-\mathbf{B} * \mathbf{P}_{\mathbf{D}}\right) \leq \mathbf{F G}_{\mathbf{E}, \max } \boldsymbol{\mu}_{\mathbf{E}} \\
& \mathbf{P T D F}_{\mathbf{C}} *\left(\mathbf{A} * \mathbf{P}-\mathbf{B} * \mathbf{P}_{\mathbf{D}}\right) \leq \mathbf{F G}_{\mathbf{C}} \boldsymbol{\mu}_{\mathbf{C}} \\
& 0 \leq F G_{k q b t}^{C} \leq F G_{k q}^{C, \max } * \hat{Y}_{j q t} \\
& 0 \leq F G_{(k+1) q b t}^{C} \leq F G_{(k+1) q}^{C, \max } * \hat{Y}_{j q t} \quad \forall j, k=2 * j-1 \\
& 0 \leq P G_{i h b t}^{E} \leq P G_{i h}^{E, \max } \forall i, \forall h \\
& 0 \leq P G_{i h b t}^{C} \leq P G_{i h}^{C, \max } * \hat{X}_{i h t} \quad \forall i, \forall h .
\end{aligned}
$$

In this subproblem, we use a dc load flow model for energy and transmission auction. The first two terms in the objective function (26) represent offers by existing and candidate generating units. The third term represents offers by TRANSCOs for providing the incremental flowgate capacity $F G_{k q b t}^{C}$ at bid price $F B I D_{\text {kqbt }}^{C}(\$ / \mathrm{MWh})$. It is assumed that GENCOs and TRANSCOs provide the ISO with investment schedules and technical information on capacity planning. Therefore, bidding prices in the operation problem are those projected by the ISO, which are based on technological and historical data. The bidding behavior might change depending on system configuration. A discussion of bidding price prediction is beyond the scope of this paper. Instead, in the case studies, we simply assume that bidding prices generation units and transmission lines are equal to operating costs and levelized investment costs, respectively. The decision variables in this problem are $P G_{i h b t}^{E}, P G_{i h b t}^{C}$ and $F G_{k q b t}^{C}$. The first constraint (27) is the system energy balance. Constraints (28) and (29) are for the existing transmission line flows and the candidate flowgates capacity, respectively. We let the flow in each direction on a transmission line be a constraint. Transmission flow constraints are linearized using power transfer distribution factors (PTDFs) [30]. PTDF $_{\mathbf{E}}$ is for existing flowgates and $\mathbf{P T D F} \mathbf{F}_{\mathbf{C}}$ is for candidate flowgates which depend on candidate transmission line installation status $\hat{Y}_{j q t}$.

Lagrangian multipliers for auction constraints are $\rho_{b t}, \boldsymbol{\mu}_{\mathrm{E}}$ and $\boldsymbol{\mu}_{\mathrm{C}}$. The dual variable $\rho_{b t}$ is the shadow price for energy. That is $\rho_{b t}$ contains marginal energy component of LMP [31], [32]. The dual variable $\boldsymbol{\mu}_{\mathrm{E}}$ is the shadow price of existing transmission network constraints. Similarly, the dual variable $\mu_{\mathrm{C}}$ is the shadow price for flowgate capacity. That is, $\boldsymbol{\mu}_{\mathrm{C}}$ contains the flowgate marginal prices, i.e., FMP for candidate flowgates.

Two possibilities may occur for (29). One is that the power flow on a candidate flowgate is equal to the dispatched capacity

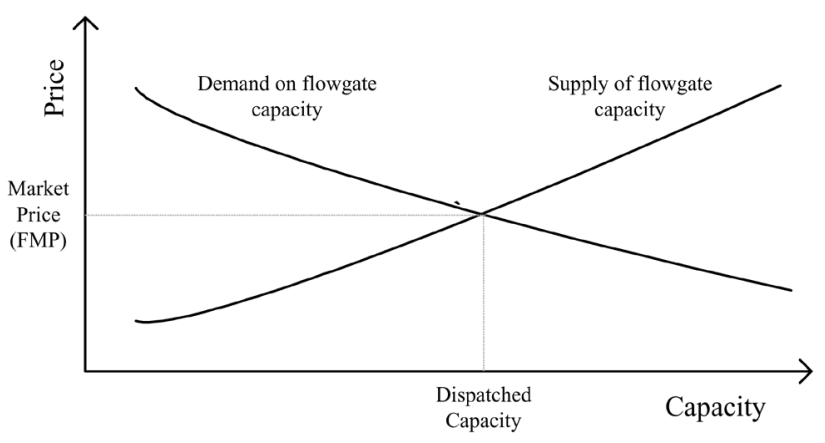

Fig. 3. Market price of candidate flowgate capacity.

of candidate flowgate, when the power flow direction is the same as that of the candidate flowgate capacity. Thus, the power flow due to net injections $\left(\mathbf{A} * \mathbf{P}-\mathbf{B} * \mathbf{P}_{\mathbf{D}}\right)$ and $\mathbf{P T D F} \mathbf{F}_{\mathbf{C}}$ can be interpreted as the demand on flowgate capacity while the dispatched flowgate capacity $\mathbf{F} \mathbf{G}_{\mathbf{C}}$ can be interpreted as the supply of flowgate capacity. Accordingly, the market clearing price of a candidate flowgate capacity is at the point where supply and demand curves cross in Fig. 3. The other is that no dispatched capacity of candidate flowgate is required for a negative power flow when the power flow direction is opposite to that of the candidate flowgate capacity. Because there is no physical meaning for the negative demand on flowgate capacity, no corresponding curve is shown in Fig. 3. Then, LMPs are defined as $\rho_{b t}+\mathbf{P T D F}^{\mathbf{T}} \boldsymbol{\mu}$ [31], [32]. A payment for dispatchable flowgate is based on FMPs and that for generation is based on LMPs.

\section{F. Stopping Criteria}

Since it is assumed that the ISO has no information on operation costs and investment costs of facilities in the market environment, the social cost is not used as stopping criteria. The ISO may stop the coordinated planning process based on some given information. Here, once the new capacity is determined and optimal operation is calculated, the sum of capacity payments determined at the security assessment stage and the system as-bid costs at the optimal operation stage can be calculated as

$$
\begin{aligned}
\phi= & \sum_{t=1}^{N T} \sum_{b=1}^{N S} \sum_{h=1}^{N G C} \sum_{i=1}^{E G_{h}} \frac{D T_{b t} *\left(P B I D_{i h b t}^{E} * P G_{i h b t}^{E}\right)}{(1+d)^{(t-1)}} \\
& +\sum_{t=1}^{N T} \sum_{b=1}^{N S} \sum_{h=1}^{N G C} \sum_{i=1}^{C G_{h}} \frac{D T_{b t} *\left(P B I D_{i h b t}^{C} * P G_{i h b t}^{C}\right)}{(1+d)^{(t-1)}} \\
& +\sum_{t=1}^{N T} \sum_{b=1}^{N S} \sum_{h=1}^{N G C} \sum_{i=1}^{C G_{h}} \frac{D T_{b t} *\left(\alpha_{i h b t} * X_{i h t}\right)}{(1+d)^{(t-1)}} \\
& +\sum_{t=1}^{N T} \sum_{b=1}^{N S} \sum_{q=1}^{N T C} \sum_{k=1}^{C F_{q}} \frac{D T_{b t} *\left(F B I D_{k q b t}^{C} * F G_{k q b t}^{C}\right)}{(1+d)^{(t-1)}} \\
& +\sum_{t=1}^{N T} \sum_{b=1}^{N S} \sum_{q=1}^{N T C} \sum_{j=1}^{C L_{q}} \frac{D T_{b t} *\left(\beta_{j q b t} * Y_{j q t}\right)}{(1+d)^{(t-1)}} .
\end{aligned}
$$

If the change in the value of $\phi$ is less than a small $\varepsilon$ value, the iteration will stop. The convergence criterion (34) is represented as follows:

$$
1-\phi^{\text {new }} / \phi^{\text {old }} \leq \varepsilon
$$




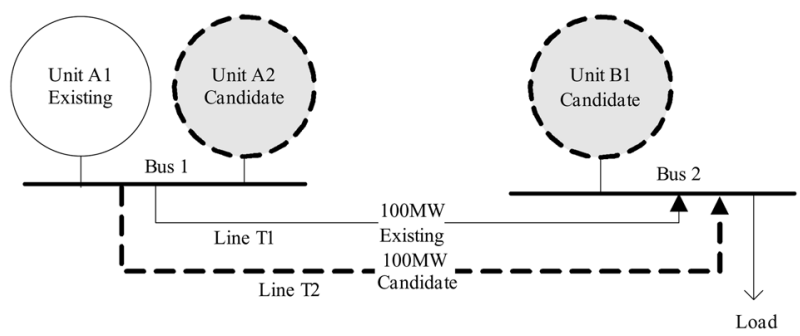

Fig. 4. Two-bus system.

TABLE I

GENERATOR DATA OF TWO-BuS SYSTEM

\begin{tabular}{|c|c|c|c|c|}
\hline GENCO & U. & $\begin{array}{c}\text { Generating } \\
\text { Capacity (MW) }\end{array}$ & $\begin{array}{c}\text { Investment Cost } \\
\text { (Thousand \$/ } \\
\text { MW/Year) }\end{array}$ & $\begin{array}{c}\text { Operation } \\
\text { Cost } \\
\text { (\$/MWh) }\end{array}$ \\
\hline \multirow{2}{*}{ A } & A1 & 100 & Existing & 30 \\
\cline { 2 - 5 } & A2 & 50 & 100 & 30 \\
\hline B & B1 & 50 & 150 & 70 \\
\hline
\end{tabular}

TABLE II

LOAD FORECASTS OF THE TWO-BUS SYSTEM (MW)

\begin{tabular}{|c|c|c|c|c|c|}
\hline Year & $\mathbf{1}$ & $\mathbf{2}$ & $\mathbf{3}$ & $\mathbf{4}$ & $\mathbf{5}$ \\
\hline Peak & 100 & 110 & 120 & 130 & 140 \\
\hline Off-Peak & 80 & 88 & 96 & 104 & 120 \\
\hline
\end{tabular}

\section{CASE STUdies}

Case studies for analyzing the effectiveness of the proposed model include a two-bus system and the modified IEEE 30-bus system. The software code is written in $\mathrm{C}++$ and solved on a 3.2 GHz Pentium 4 PC.

\section{A. Two-Bus System}

The two-bus case study is applied in a 5-year planning horizon to show the effectiveness of the proposed model by a simple system that can also be solved intuitively. The existing and candidate generating units of GENCOs A and B, located at buses 1 and 2, respectively, are represented by equivalent generating units in Fig. 4. The generator data and load forecasts over the planning horizon are shown in Tables I and II.

The capacity of existing and candidate transmission lines is $100 \mathrm{MW}$ each with a reactance of $0.15 \mathrm{pu}$. Each year is represented by peak and off-peak subperiods. The only load is at bus 2 . The cost of transmission investment is $10000 \$ / \mathrm{MW} /$ Year and the operating cost is assumed negligible. Generating units are assumed to bid their operating cost and flowgate bid is assumed to be a levelized investment cost [28]. For simplicity, the discount rate is assumed to be 0 . The stopping criterion $\varepsilon$ is $1 \%$.

Two cases of generation planning (Case G) and coordinated transmission and generation planning (Case $\mathbf{T} \& \mathbf{G}$ ) are considered. The GENCO A's operation and investment costs of candidate generating unit are cheaper than those of GENCO B. GENCO A's candidate generating unit A2 at bus 1 is located remotely from the load at bus 2 . Table III shows social costs and market participant profits. Table IV shows the capacity installation status for generating units and transmission lines in each case and incentives for capacity addition $\left(\alpha_{i h b t}\right.$ and $\left.\beta_{j q b t}\right)$. Incentives are capacity signals that represent funds received by
TABLE III

SOCIAL COSTS AND PARTICIPANT'S PROFIT

\begin{tabular}{|c|c|c|c|c|}
\hline \multirow{2}{*}{ Case } & \multirow{2}{*}{$\begin{array}{c}\text { Social Cost } \\
\text { (Million\$) }\end{array}$} & \multicolumn{3}{|c|}{ Profit (\$) } \\
\cline { 3 - 5 } & 188.6 & GENCO A & GENCO B & TRANSCO \\
\hline G & 160.3 & 16,600 & 24,900 & 0 \\
\hline T\&G & & \multicolumn{3}{|c}{} \\
\hline
\end{tabular}

TABLE IV

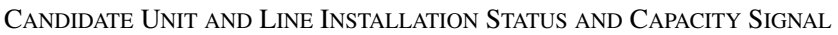

\begin{tabular}{|c|c|c|c|c|c|c|c|}
\hline \multirow{2}{*}{ Case } & \multirow{2}{*}{ Unit } & \multirow{2}{*}{$\begin{array}{c}\text { Installation } \\
\text { year }\end{array}$} & \multicolumn{5}{|c|}{$\begin{array}{c}\text { Capacity signal } \\
\text { (Thousand \$/MW) }\end{array}$} \\
\cline { 4 - 8 } & & & Year 1 & Year 2 & Year 3 & Year 4 & Year 5 \\
\hline \multirow{2}{*}{ G } & $\mathbf{A 2}$ & Not installed & 0 & 0 & 0 & 0 & 0 \\
\cline { 2 - 8 } & $\mathbf{B 1}$ & Year 2 & 0 & 151.6 & 148.9 & 152.4 & 147.6 \\
\hline \multirow{3}{*}{ T\&G } & $\mathbf{A 2}$ & Year 2 & 0 & 101.6 & 101.6 & 99.9 & 97.2 \\
\cline { 2 - 8 } & $\mathbf{B 1}$ & Not installed & 0 & 113.4 & 107.8 & 111.3 & 106.0 \\
\cline { 2 - 8 } & $\mathbf{T 2}$ & Year 2 & 0 & 11.8 & 6.1 & 11.4 & 8.8 \\
\hline
\end{tabular}

TABLE V

LMP at LOAD BUS AND FMP FOR CANDIDATE LINE DURING PEAK (\$/MWH)

\begin{tabular}{|c|c|c|c|c|c|c|}
\hline \multirow{2}{*}{\multicolumn{2}{|c|}{ Case }} & \multicolumn{5}{|c|}{ Year } \\
\hline & & \multirow{2}{*}{$\frac{1}{30.00}$} & \multirow{2}{*}{$\frac{\mathbf{2}}{70.00}$} & \multirow{2}{*}{$\frac{3}{70.00}$} & \multirow{2}{*}{$\begin{array}{c}4 \\
70.00 \\
\end{array}$} & \multirow{2}{*}{$\begin{array}{r}\mathbf{5} \\
70.00\end{array}$} \\
\hline LMP & G & & & & & \\
\hline (\$/MWh) & T\&G & 30.00 & 30.14 & 30.14 & 30.14 & 30.14 \\
\hline \multirow{2}{*}{$\underset{\text { (\$/MWh) }}{\text { FMP }}$} & G & 0 & 0 & 0 & 0 & 0 \\
\hline & T\&G & 0 & 0.28 & 0.28 & 0.28 & 0.28 \\
\hline
\end{tabular}

installed generating units and transmission lines. In Case $\mathrm{T} \& \mathrm{G}$, capacity signal for $\mathrm{B} 1$ in year 2 and beyond represents funds that $\mathrm{B} 1$ would have received if installed in year 2 . Table $\mathrm{V}$ shows the LMP at bus load and FMP for candidate transmission line during the peak season. Table VI shows the dispatched capacity of generating units and transmission power flows during the peak season.

Case G: Tables IV and VI show that generating unit B1 located at bus 2 is installed in year 2 to meet the load at bus 2 while the transmission line capacity is limited to $100 \mathrm{MW}$. This means the ISO provides generating unit B1 with a high capacity payment to make it profitable even though the high operating cost prevents GENCO B from making any profit from energy sales. The incentive for adding generating unit $\mathrm{A} 2$ to bus 1 is zero because the new generating unit at bus 1 will not contribute to the reduction of load curtailment at bus 2 when the transmission line capacity is limited. Table $\mathrm{V}$ shows that, beyond year 2 , the peak season LMP at bus 2 is determined by the high operating cost of generating unit B1.

Case T\&G: Table IV shows that generating unit A2 at bus 1 and transmission line T2 are installed as transmission and generation planning are coordinated. Although, the revenue from the auction is short of investment cost recovery, the capacity payment enables the installation of transmission line T2. Once the transmission line capacity is added, generating unit A2 located remotely from the load becomes profitable and installed accordingly. Even though the value of generation capacity addition at bus 2 is still higher than that at bus 1 , generating unit B1 cannot be profitable due to high operation and investment costs. TRANSCO would make a profit through market revenues 
TABLE VI

DisPatched Unit CAPACITY AND Line Power Flows DuRING PEAK

\begin{tabular}{|c|c|c|c|c|c|c|}
\hline \multicolumn{2}{|c|}{ Year } & 1 & 2 & 3 & 4 & 5 \\
\hline \multicolumn{7}{|c|}{ Dispatched capacity of generating unit (MW) } \\
\hline \multirow{3}{*}{$\begin{array}{c}\text { Case } \\
\mathbf{G}\end{array}$} & $\mathbf{A 1}$ & 100 & 100 & 100 & 100 & 100 \\
\hline & $\mathbf{A 2}$ & 0 & 0 & 0 & 0 & 0 \\
\hline & B1 & 0 & 10 & 20 & 30 & 40 \\
\hline \multirow{3}{*}{$\begin{array}{l}\text { Case } \\
\text { T\&G }\end{array}$} & $\mathbf{A 1}$ & 100 & 100 & 100 & 100 & 100 \\
\hline & $\mathbf{A 2}$ & 0 & 10 & 20 & 30 & 40 \\
\hline & B1 & 0 & 0 & 0 & 0 & 0 \\
\hline \multicolumn{7}{|c|}{ Power flow on Transmission line (MW) } \\
\hline \multirow{2}{*}{$\begin{array}{c}\text { Case } \\
\text { G }\end{array}$} & T1 & 100 & 100 & 100 & 100 & 100 \\
\hline & $\mathbf{T 2}$ & 0 & 0 & 0 & 0 & 0 \\
\hline \multirow{2}{*}{$\begin{array}{c}\text { Case } \\
\text { T\&G }\end{array}$} & T1 & 100 & 55 & 60 & 65 & 70 \\
\hline & T2 & 0 & 55 & 60 & 65 & 70 \\
\hline
\end{tabular}

and capacity payment as reflected in Table III. The two-bus case shows that the proposed model would incorporate merchant transmission line into capacity planning.

The settlement is configured based on LMP and FMP values in Table $\mathrm{V}$ and dispatched generation capacity and power flows in Table VI. FMP is nonzero because a positive FBID price has been submitted for that flowgate based upon the long term levelized cost, as assumed earlier in the paper. The power flow of candidate transmission line $\mathrm{T} 2$ is interpreted as the dispatched capacity of transmission line T2. For example, during the peak load season in year 3, the load at bus 2 pays (LMP $*$ load at bus $2=\$ 3616.8 / h$ ) while GENCO A at bus 1 receives (LMP * dispatched generation capacity at bus $1=\$ 3600 / h$ ) and TRANSCO receives (FMP of $\$ 0.28 / \mathrm{MWh} *$ power flow at T2 of $60 \mathrm{MW}=\$ 16.8 / h)$.

In Table III, the social costs, defined as the sum of operation costs and investment costs, are calculated from the simulation results. A considerable saving is achieved by coordinated planning as the social cost of generation planning is higher than that of coordinated capacity planning by $\$ 28.3$ million. This simple and intuitively solvable example shows the effectiveness of the proposed model for holistic simulation of transmission and generation capacity expansion in electricity markets while exploring the value of candidate generating units and transmission lines to the system security.

Note that when the capacity payments for candidate units A2 and B1 are instead levelized over four operating years (rather than varying from year to year), it is found that this capacity payment set also results in the same installation schedule. Thus, it is possible to get more than one set of capacity payments that support a given solution during the LR loop shown in Fig. 2. When multiple sets of capacity payments are calculated with the same present values and installation schedules for each player, the ISO might need a pre-defined rule for determining which set of capacity payments will be applied to market players. For example, the one with the least variation over the planning period could be selected by the ISO.

In addition, it is assumed in our model that the ISO has no indication of the true investment costs of GENCOs or TRANSCOs. Therefore, the ISO may not be able to supply the optimal capacity payment. For example, in this case, the capacity payment to unit A2 over the four operating years is
TABLE VII

CANDidate Generators Data of the 30-Bus System

\begin{tabular}{|c|c|c|c|c|}
\hline Unit & Bus & $\begin{array}{c}\text { Capacity } \\
\text { (MW) }\end{array}$ & $\begin{array}{c}\text { Operating Cost } \\
\text { (\$/MWh) }\end{array}$ & $\begin{array}{c}\text { Investment Cost } \\
\text { (Thousand \$/MW/year) }\end{array}$ \\
\hline A1 & 4 & 10 & 46.66 & 50 \\
\hline A2 & 7 & 10 & 44.12 & 70 \\
\hline A3 & 23 & 20 & 21.32 & 80 \\
\hline A4 & 25 & 20 & 15.38 & 150 \\
\hline B1 & 13 & 20 & 24.15 & 100 \\
\hline B2 & 15 & 20 & 22.56 & 120 \\
\hline B3 & 17 & 10 & 22.56 & 80 \\
\hline B4 & 7 & 10 & 46.66 & 30 \\
\hline B5 & 8 & 10 & 46.66 & 40 \\
\hline B6 & 9 & 20 & 15.38 & 130 \\
\hline B7 & 4 & 20 & 44.12 & 60 \\
\hline
\end{tabular}

TABLE VIII

CANDidate TRANSmission Line Data of 30-Bus System

\begin{tabular}{|c|c|c|c|c|c|}
\hline Line & From & To & Capacity & $\mathbf{X}$ (p.u) & $\begin{array}{c}\text { Investment Cost } \\
\text { (Thousand \$/MW/year) }\end{array}$ \\
\hline T1 & 1 & 2 & 30 & 0.0575 & 10 \\
\hline T2 & 1 & 3 & 30 & 0.1852 & 25 \\
\hline T3 & 2 & 4 & 30 & 0.1737 & 15 \\
\hline T4 & 3 & 4 & 30 & 0.0379 & 10 \\
\hline T5 & 9 & 10 & 30 & 0.11 & 14 \\
\hline T6 & 12 & 13 & 65 & 0.14 & 9 \\
\hline T7 & 9 & 11 & 30 & 0.208 & 8 \\
\hline T8 & 4 & 12 & 65 & 0.256 & 5 \\
\hline
\end{tabular}

400.3 thousand $\$ / \mathrm{MW}$, which is larger than its investment cost of 400 thousand $\$ / M W$ in these years. Our algorithm for determining the capacity payment is an iterative process in which the capacity payment is increased if the installation schedule is feasible and decreased otherwise. If step size for altering the capacity payment is small and the number of iterations is large, our model could result in a smaller capacity payment.

\section{B. Modified IEEE 30-Bus System}

The modified IEEE 30-bus system has 41 existing transmission lines, 20 demand sides and seven existing generating units. The modified IEEE 30-bus system data and forecasted load for ten year planning horizon are given in the Appendix. Certain candidate generator and transmission line data are shown in Tables VII and VIII. Candidate generating units A1, A2, A3, A4 belong to GENCO A and B1, B2, B3, B4, B5, B6, B7 belong to GENCO B. Generating units A4 and B6 (which have lower operating costs) and B1 are located remotely from the load and remaining generating units are located at load buses. Candidate generating units have the same capacity and operating costs except for their locations. Hence, the cost of a candidate generating unit investment is assumed to be a function of its location. This assumption is intended to analyze the impact of generation unit location on generation capacity planning. A discount rate of $5 \%$ is used in the calculation of net present value and capacity payment for new generating units and transmission lines. The stopping criterion $\varepsilon$ is $1 \%$.

A planning year is divided into 4 subperiods for representing seasonal load patterns. Similar to the first case study, we consider two test cases of generation capacity planning, and coor- 
TABLE IX

GENERATING UNITS INSTALLATION YeAR: CASE G

\begin{tabular}{|c|c|c|c|c|c|c|c|c|c|c|c|}
\hline Unit & A1 & A2 & A3 & A4 & B1 & B2 & B3 & B4 & B5 & B6 & B7 \\
\hline Year & 2 & 0 & 3 & 8 & 2 & 5 & 1 & 9 & 7 & 0 & 5 \\
\hline
\end{tabular}

TABLE $X$

Generating Unit REVENUE From CAPACITy PAyMENT (THOUSANDS OF \$/MW)

\begin{tabular}{|c|c|c|c|c|c|c|c|c|c|c|c|}
\hline Unit & A1 & A2 & A3 & A4 & B1 & B2 & B3 & B4 & B5 & B6 & B7 \\
\hline Yr 1 & 0 & 0 & 0 & 0 & 0 & 0 & 32.5 & 0 & 0 & 0 & 0 \\
\hline Yr 2 & 0 & 0 & 0 & 0 & 0 & 0 & 0 & 0 & 0 & 0 & 0 \\
\hline Yr 3 & 0 & 0 & 0 & 0 & 0 & 0 & 0 & 0 & 0 & 0 & 0 \\
\hline Yr 4 & 29.3 & 0 & 28.6 & 0 & 29.1 & 0 & 29.2 & 0 & 0 & 0 & 0 \\
\hline Yr 5 & 20.5 & 0 & 21.5 & 0 & 26.4 & 28.0 & 29.3 & 0 & 0 & 0 & 20.5 \\
\hline Yr 6 & 20.0 & 0 & 17.0 & 0 & 23.1 & 24.1 & 23.6 & 0 & 0 & 0 & 20.0 \\
\hline Yr 7 & 33.8 & 0 & 32.0 & 0 & 33.8 & 33.8 & 33.8 & 0 & 24.6 & 0 & 33.8 \\
\hline Yr 8 & 43.4 & 0 & 63.4 & 55.1 & 59.0 & 61.9 & 72.0 & 0 & 34.7 & 0 & 43.4 \\
\hline Yr 9 & 42.5 & 0 & 62.2 & 54.0 & 57.9 & 60.7 & 70.6 & 29.1 & 34.0 & 0 & 42.5 \\
\hline Yr 10 & 51.1 & 0 & 74.7 & 64.8 & 69.5 & 72.9 & 84.8 & 34.9 & 40.8 & 0 & 51.1 \\
\hline
\end{tabular}

TABLE XI

Generating Unit Revenue From Auction (Thousands of \$/MW)

\begin{tabular}{|c|c|c|c|c|c|c|c|c|c|c|c|}
\hline Unit & A1 & A2 & A3 & A4 & B1 & B2 & B3 & B4 & B5 & B6 & B7 \\
\hline Yr 1 & 0 & 0 & 0 & 0 & 0 & 0 & 352.6 & 0 & 0 & 0 & 0 \\
\hline Yr 2 & 106.5 & 0 & 0 & 0 & 136.5 & 0 & 156.0 & 0 & 0 & 0 & 0 \\
\hline Yr 3 & 106.5 & 0 & 156.1 & 0 & 118.9 & 0 & 156.0 & 0 & 0 & 0 & 0 \\
\hline Yr 4 & 187.9 & 0 & 99.1 & 0 & 246.5 & 0 & 211.5 & 0 & 0 & 0 & 0 \\
\hline Yr 5 & 109.3 & 0 & 156.6 & 0 & 131.1 & 157.5 & 156.0 & 0 & 0 & 0 & 109.3 \\
\hline Yr 6 & 136.5 & 0 & 243.3 & 0 & 224.5 & 225.0 & 228.7 & 0 & 0 & 0 & 136.5 \\
\hline Yr 7 & 136.5 & 0 & 274.9 & 0 & 236.3 & 236.6 & 239.9 & 0 & 118.5 & 0 & 172.0 \\
\hline Yr 8 & 136.5 & 0 & 219.7 & 260.9 & 213.0 & 213.4 & 216.7 & 0 & 118.5 & 0 & 136.5 \\
\hline Yr 9 & 136.5 & 0 & 256.0 & 292.2 & 236.3 & 236.6 & 239.9 & 105.5 & 118.5 & 0 & 154.3 \\
\hline Yr 10 & 165.0 & 0 & 168.9 & 288.1 & 295.0 & 314.2 & 272.2 & 122.8 & 138.1 & 0 & 217.8 \\
\hline
\end{tabular}

dinated transmission and generation capacity planning. For the 30-bus coordinated transmission and generation planning case (Case T\&G), the value of $M$ is equal to 100 and the maximum number of Lagrangian relaxation iterations is set at 200. The solution requires 15 price iterations and takes $656 \mathrm{~s}$.

Case G: Table IX shows the generating unit installation in planning years. Tables $\mathrm{X}$ and XI show capacity payments and auction market revenues, respectively, for generating units. As expected, generating units located at load bus with a relatively lower operation or investment cost are installed in earlier years. For example, generating unit B3 is installed in year 1 according to its favorable location with $\$ 32.5 * 1000 / \mathrm{MW}$ of capacity payment and $\$ 352.6 * 1000 / \mathrm{MW}$ from the auction market in year 1. Generating units $\mathrm{A} 1$ and $\mathrm{B} 1$ are installed in year 2 and $\mathrm{A} 3$ in year 3 because the unit A1 is located at the load bus 4 and units $\mathrm{A} 3$ and B1 have relatively lower operation and investment costs, which generate enough market revenues without receiving capacity payments in early years. Generating unit B7 is installed in year 5 to supply the load growth at bus 4 . Table $X$ shows that generating units A4 with high investment cost, and B4 and B5 with high operating costs are installed when the capacity payment is sufficiently large following the load growth. Generating units A2 and B6 are not installed due to high operating cost of generating unit $\mathrm{A} 2$ and unfavorable location of generating unit
TABLE XII

Transmission Revenue From the Auction Market (THOUSANDS OF \$/MW)

\begin{tabular}{|c|c|c|c|c|c|c|c|c|}
\hline Line & T1 & T2 & T3 & T4 & T5 & T6 & T7 & T8 \\
\hline Yr 1 & 0 & 0 & 0 & 0 & 0 & 0 & 0 & 0 \\
\hline Yr 2 & 0 & 0 & 0 & 0 & 0 & 0 & 0 & 0 \\
\hline Yr 3 & 101.6 & 0 & 2.6 & 0 & 0 & 0 & 0 & 0 \\
\hline Yr 4 & 101.8 & 0 & 2.7 & 0 & 0 & 0 & 0 & 0 \\
\hline Yr 5 & 61.8 & 4.6 & 2.4 & 1.7 & 0 & 0 & 0 & 0 \\
\hline Yr 6 & 19.0 & 4.7 & 2.5 & 1.8 & 0 & 0 & 0 & 0 \\
\hline Yr 7 & 23.6 & 4.8 & 2.6 & 1.8 & 1.5 & 0 & 0 & 0.3 \\
\hline Yr 8 & 19.0 & 4.8 & 2.6 & 1.8 & 1.5 & 0 & 0 & 0.3 \\
\hline Yr 9 & 19.0 & 4.8 & 2.6 & 1.8 & 1.6 & 0 & 0 & 0.3 \\
\hline Yr 10 & 19.0 & 4.8 & 2.6 & 1.8 & 1.6 & 0 & 0 & 0.3 \\
\hline
\end{tabular}

TABLE XIII

Transmission Line ReVEnUe From CaPacity Payment (THOUSANDS OF \$/MW)

\begin{tabular}{|c|c|c|c|c|c|c|c|c|}
\hline Line & T1 & T2 & T3 & T4 & T5 & T6 & T7 & T8 \\
\hline Yr 1 & 0 & 0 & 0 & 0 & 0 & 0 & 0 & 0 \\
\hline Yr 2 & 0 & 0 & 0 & 0 & 0 & 0 & 0 & 0 \\
\hline Yr 3 & 10.1 & 0 & 24.2 & 0 & 0 & 0 & 0 & 0 \\
\hline Yr 4 & 30.9 & 0 & 19.6 & 0 & 0 & 0 & 0 & 0 \\
\hline Yr 5 & 15.5 & 45.5 & 27.6 & 25.6 & 0 & 0 & 0 & 0 \\
\hline Yr 6 & 20.4 & 65.7 & 39.3 & 37.6 & 0 & 0 & 0 & 0 \\
\hline Yr 7 & 8.5 & 16.0 & 10.0 & 3.3 & 16.3 & 0 & 0 & 5.8 \\
\hline Yr 8 & 3.1 & 6.2 & 4.8 & 1.3 & 30.0 & 0 & 0 & 11.2 \\
\hline Yr 9 & 0 & 0 & 0 & 0 & 0 & 0 & 0 & 0 \\
\hline Yr 10 & 0.2 & 0.6 & 0.9 & 0.1 & 21.5 & 0 & 0 & 5.1 \\
\hline
\end{tabular}

B6. Note that the same capacity payments are offered to all participants located at the same bus. For example, in the 30-bus case, units A1 and B7 which are located at the same bus receive the same payment as listed in the Table $\mathrm{X}$, while the capacity payment to B7 in year 4 is zero because it is not installed in year 4.

Case T\&G: Table XII shows that candidate transmission lines except $\mathrm{T} 1$ cannot earn sufficient revenues from the auction market participation to recover their investment costs. Hence, for most candidate transmission lines, additional payment is required in order to entice any market-based transmission investments. Table XIII shows that the capacity payment provides merchant transmission lines with additional revenues effectively. Thus, the capacity payment plays a significant role in transmission investment when the market revenue is short of the investment cost recovery.

Within year 9, either dual variables $(\gamma$ and $\phi)$ of (11) and (13) or multiplier $\pi$, which determine the capacity signal, are zero. This means that the transmission capacity proposed by the TRANSCO is large enough to satisfy the security constraint in year 9. Table XIV shows that candidate transmission lines T1 and T3 are installed in year 3 when revenues from capacity payment and auction market are sufficient to recover investment costs. Similarly, transmission lines T2 and T4 are installed in year 5 and transmission lines T5 and T8 are installed in year 7. Transmission lines T6 and T7 are not installed because of their minor impact on system security; in other words, capacity payment does not provide sufficient revenues to recover investment costs. 
TABLE XIV

TRANSMISSION LINE INSTALLATION YEAR: CASE T\&G

\begin{tabular}{|c|c|c|c|c|c|c|c|c|}
\hline Line & T1 & T2 & T3 & T4 & T5 & T6 & T7 & T8 \\
\hline Year & 3 & 5 & 3 & 5 & 7 & 0 & 0 & 7 \\
\hline
\end{tabular}

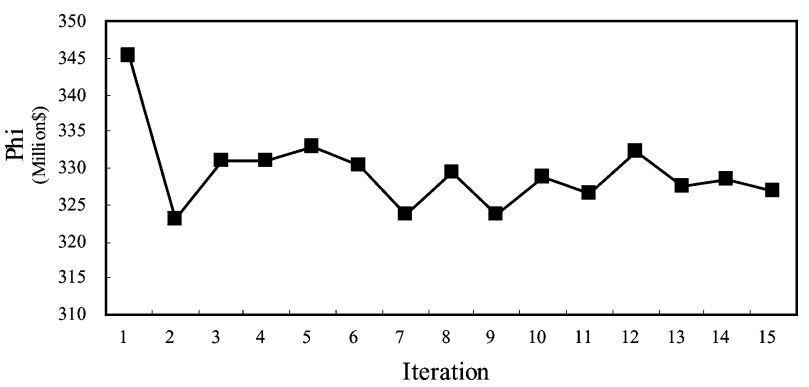

Fig. 5. Convergence performance in Case T\&G.

TABLE XV

GENERATING UNIT INSTALLATION YeAR: CASE T\&G

\begin{tabular}{|c|c|c|c|c|c|c|c|c|c|c|c|}
\hline Unit & A1 & A2 & A3 & A4 & B1 & B2 & B3 & B4 & B5 & B6 & B7 \\
\hline Year & 2 & 0 & 1 & 0 & 4 & 0 & 1 & 6 & 8 & 0 & 9 \\
\hline
\end{tabular}

TABLE XVI

FinANCIAL RESULTS (MILLIONS OF \$)

\begin{tabular}{|c|c|c|c|c|}
\hline \multirow{2}{*}{ Case } & \multirow{2}{*}{ Social cost } & \multicolumn{3}{|c|}{ Profit } \\
\cline { 3 - 5 } & & GENCO A & GENCO B & TRANSCO \\
\hline G & 399.6 & 101.5 & 17.2 & 0.0 \\
\hline T\&G & 347.5 & 174.2 & 5.3 & 11.8 \\
\hline
\end{tabular}

Table XV shows that the installation pattern of generating units in the Case $T \& G$ is quite different from that of Case $G$ because the new transmission network configuration affects the additional value of candidate generating units. Compared with Case G, generating units A4 and B2 with high investment costs are not installed. The installation of $\mathrm{A} 3$ and $\mathrm{B} 4$ are shifted to earlier years and that of B1, B5, and B7 are delayed in order to avoid the year when transmission line is installed. The social cost iteration is shown in Fig. 5 in which the solution reaches equilibrium in 15 price iterations. The social cost oscillations in this figure are due to changes in GENCOs' and TRANSCOs' capacity investment decisions which are based on prospective prices.

Table XVI compares market participants' profit in Cases G and T\&G. The profit of GENCO A in the coordinated planning model is increased as compared with that in generation-only planning because existing generating units take advantage of transmission capacity expansion. On the contrary, the profit of GENCO B is decreased because GENCO B has fewer investment opportunities in its competition with TRANSCO. As in the two-bus case study, the TRANSCO's profit is due to revenues from auction market and capacity payments. Table XVI shows that the social cost is reduced by $\$ 45.5$ million (i.e., considerable saving) when transmission and generation capacity are planned simultaneously. This more realistic case study shows the effectiveness of proposed model for the market-based coordination of generation and transmission capacity planning.
TABLE XVII

LOAD DISTRIBUTION BY BUS

\begin{tabular}{|c|c|c|c|c|c|}
\hline Bus & $\mathbf{1}$ & $\mathbf{2}$ & $\mathbf{3}$ & $\mathbf{4}$ & $\mathbf{5}$ \\
\hline Distribution & 0.00 & 0.08 & 0.01 & 0.20 & 0.12 \\
\hline Bus & $\mathbf{6}$ & $\mathbf{7}$ & $\mathbf{8}$ & $\mathbf{9}$ & $\mathbf{1 0}$ \\
\hline Distribution & 0.00 & 0.08 & 0.10 & 0.00 & 0.07 \\
\hline Bus & $\mathbf{1 1}$ & $\mathbf{1 2}$ & $\mathbf{1 3}$ & $\mathbf{1 4}$ & $\mathbf{1 5}$ \\
\hline Distribution & 0.00 & 0.08 & 0.00 & 0.02 & 0.03 \\
\hline Bus & $\mathbf{1 6}$ & $\mathbf{1 7}$ & $\mathbf{1 8}$ & $\mathbf{1 9}$ & $\mathbf{2 0}$ \\
\hline Distribution & 0.01 & 0.03 & 0.01 & 0.02 & 0.01 \\
\hline Bus & $\mathbf{2 1}$ & $\mathbf{2 2}$ & $\mathbf{2 3}$ & $\mathbf{2 4}$ & $\mathbf{2 5}$ \\
\hline Distribution & 0.06 & 0.00 & 0.01 & 0.02 & 0.00 \\
\hline Bus & $\mathbf{2 6}$ & $\mathbf{2 7}$ & $\mathbf{2 8}$ & $\mathbf{2 9}$ & $\mathbf{3 0}$ \\
\hline Distribution & 0.01 & 0.00 & 0.00 & 0.00 & 0.02 \\
\hline
\end{tabular}

\section{CONCLUSIONS}

The proposed market-based model simulated the interactions among market participants (GENCOs and TRANSCO), and the interaction between the ISO and market participants. This model could provide signals to investors on the location of new generation and transmission facilities and help system planners, regulators, and local authorities concur on the amounts and the locations of transmission capacity planning. The tests on a two-bus system and a 30-bus system showed the effectiveness of the proposed model which can successfully coordinate the process of merchant transmission and generation capacity planning in restructured power markets.

Ancillary service markets are important revenue sources for GENCOs in restructured electricity markets. However, our model does not consider such services in order to simplify the discussion on the long term planning model. Nevertheless, the simultaneous clearing of energy and ancillary services markets can be applied by the ISO at the optimal operation stage. The market prices of ancillary services can be determined based on ancillary services constraints such as spinning and nonspinning reserves that are common in market designs and models [32]. In addition, uncertainties in load growth and contingencies are not considered in the current paper. The limit on load shedding with consideration of uncertainties would be a reliability criterion. These topics should be addressed in future research.

\section{APPENDIX}

Table XVII shows the load distribution by bus; Table XVIII shows the yearly peak load and energy demand; Table XIX shows the existing generating units characteristics; Table XX shows the load by subperiod in base year; and Table XXI shows the transmission lines characteristics.

The subperiod load calculation via the linear transformation of base year's corresponding subperiod load is as follows:

$$
L_{b t}=a \times L_{b 0}+b .
$$

a

$b$

$$
\begin{aligned}
& \left(E_{t}-H \times P_{t}\right) /\left(E_{0}-H \times P_{0}\right) . \\
& \left(P_{t} \times E_{0}-P_{0} \times E_{t}\right) /\left(E_{0}-H \times P_{0}\right) .
\end{aligned}
$$


TABLE XVIII

YEARLY PEAK LOAD AND ENERGY DEMAND

\begin{tabular}{|c|c|c|c|c|c|}
\hline Year & $\mathbf{1}$ & $\mathbf{2}$ & $\mathbf{3}$ & $\mathbf{4}$ & $\mathbf{5}$ \\
\hline Peak Load (MW) & 283.4 & 303.2 & 324.5 & 347.2 & 364.5 \\
\hline Energy(GWh) & 1682.0 & 1799.7 & 1925.7 & 2060.5 & 2163.5 \\
\hline Year & $\mathbf{6}$ & $\mathbf{7}$ & $\mathbf{8}$ & $\mathbf{9}$ & $\mathbf{1 0}$ \\
\hline Peak Load (MW) & 382.8 & 401.9 & 414.0 & 426.4 & 439.2 \\
\hline Energy(GWh) & 2271.7 & 2385.2 & 2456.8 & 2530.5 & 2606.4 \\
\hline
\end{tabular}

TABLE XIX

EXISTING GENERATING UNITS CHARACTERISTICS

\begin{tabular}{|c|c|c|c|}
\hline ID & Capacity (MW) & Bus & Operating Cost (\$/MWh) \\
\hline $\mathbf{1}$ & 20 & 30 & 59.18 \\
\hline $\mathbf{2}$ & 20 & 24 & 46.66 \\
\hline $\mathbf{3}$ & 20 & 11 & 44.12 \\
\hline $\mathbf{4}$ & 80 & 2 & 21.32 \\
\hline $\mathbf{5}$ & 50 & 8 & 15.42 \\
\hline $\mathbf{6}$ & 50 & 5 & 15.38 \\
\hline $\mathbf{7}$ & 100 & 1 & 12.58 \\
\hline
\end{tabular}

TABLE XX

LOAD BY SUBPERIOD IN BASE YEAR

\begin{tabular}{|c|c|c|c|c|}
\hline Subperiod & $\mathbf{1}$ & $\mathbf{2}$ & $\mathbf{3}$ & $\mathbf{4}$ \\
\hline Peak Load (MW) & 283.4 & 255.1 & 229.6 & 206.6 \\
\hline
\end{tabular}

TABLE XXI

TRANSMISSION LINES CHARACTERISTICS

\begin{tabular}{|c|c|c|c|c|c|c|c|c|c|}
\hline ID & Fr. & To & Cap. (MW) & X (pu) & ID & Fr. & To & Cap. (MW) & X (pu) \\
\hline $\mathbf{1}$ & 1 & 2 & 30 & 0.0575 & $\mathbf{2 2}$ & 15 & 18 & 16 & 0.2185 \\
\hline $\mathbf{2}$ & 1 & 3 & 30 & 0.1852 & $\mathbf{2 3}$ & 18 & 19 & 16 & 0.1292 \\
\hline $\mathbf{3}$ & 2 & 4 & 30 & 0.1737 & $\mathbf{2 4}$ & 19 & 20 & 32 & 0.068 \\
\hline $\mathbf{4}$ & 3 & 4 & 30 & 0.0379 & $\mathbf{2 5}$ & 10 & 20 & 32 & 0.209 \\
\hline $\mathbf{5}$ & 2 & 5 & 30 & 0.1983 & $\mathbf{2 6}$ & 10 & 17 & 32 & 0.0845 \\
\hline $\mathbf{6}$ & 2 & 6 & 30 & 0.1763 & $\mathbf{2 7}$ & 10 & 21 & 30 & 0.0749 \\
\hline $\mathbf{7}$ & 4 & 6 & 30 & 0.0414 & $\mathbf{2 8}$ & 10 & 22 & 30 & 0.1499 \\
\hline $\mathbf{8}$ & 5 & 7 & 30 & 0.0116 & $\mathbf{2 9}$ & 21 & 22 & 30 & 0.0236 \\
\hline $\mathbf{9}$ & 6 & 7 & 30 & 0.082 & $\mathbf{3 0}$ & 15 & 23 & 16 & 0.202 \\
\hline $\mathbf{1 0}$ & 6 & 8 & 30 & 0.042 & $\mathbf{3 1}$ & 22 & 24 & 30 & 0.179 \\
\hline $\mathbf{1 1}$ & 6 & 9 & 30 & 0.208 & $\mathbf{3 2}$ & 23 & 24 & 16 & 0.27 \\
\hline $\mathbf{1 2}$ & 6 & 10 & 30 & 0.556 & $\mathbf{3 3}$ & 24 & 25 & 30 & 0.3292 \\
\hline $\mathbf{1 3}$ & 9 & 11 & 30 & 0.208 & $\mathbf{3 4}$ & 25 & 26 & 30 & 0.38 \\
\hline $\mathbf{1 4}$ & 9 & 10 & 30 & 0.11 & $\mathbf{3 5}$ & 25 & 27 & 30 & 0.2087 \\
\hline $\mathbf{1 5}$ & 4 & 12 & 65 & 0.256 & $\mathbf{3 6}$ & 27 & 28 & 30 & 0.396 \\
\hline $\mathbf{1 6}$ & 12 & 13 & 65 & 0.14 & $\mathbf{3 7}$ & 27 & 29 & 30 & 0.4153 \\
\hline $\mathbf{1 7}$ & 12 & 14 & 32 & 0.2559 & $\mathbf{3 8}$ & 27 & 30 & 30 & 0.6027 \\
\hline $\mathbf{1 8}$ & 12 & 15 & 32 & 0.1304 & $\mathbf{3 9}$ & 29 & 30 & 30 & 0.4533 \\
\hline $\mathbf{1 9}$ & 12 & 16 & 32 & 0.1987 & $\mathbf{4 0}$ & 8 & 28 & 30 & 0.2 \\
\hline $\mathbf{2 0}$ & 14 & 15 & 16 & 0.1997 & $\mathbf{4 1}$ & 6 & 28 & 30 & 0.0599 \\
\hline $\mathbf{2 1}$ & 16 & 17 & 16 & 0.1932 & & & & \\
\hline & & & & & & & & \\
\hline
\end{tabular}

$L_{b t} \quad$ Load at subperiod $b$ in year $t$.

$L_{b 0} \quad$ Load at subperiod $b$ in base year.

$E_{t} \quad$ Energy demand in year $t$.

$P_{t} \quad$ Peak load in year $t$.
$P_{0} \quad$ Peak load in base year.

$E_{0} \quad$ Energy demand in base year.

$H \quad$ Hours of a year.

A load distribution factor multiplied by a subperiod load provides bus loads at the subperiod.

\section{REFERENCES}

[1] M. Shahidehpour, "Investing in expansion: The many issues that cloud transmission planning," IEEE Power Energy Mag, vol. 2, no. 1, pp. 14-18, Jan./Feb. 2004.

[2] W. Li and R. Billinton, "A minimum cost assessment method for composite generation and transmission system expansion planning," IEEE Trans. Power Syst., vol. 8, no. 2, pp. 628-635, May 1993.

[3] P. Gribik, D. Shirmohammadi, J. Graves, and J. Kritikson, "Transmission rights and transmission expansions," IEEE Trans. Power Syst., vol. 20, no. 4, pp. 1728-1737, Nov. 2005.

[4] R. P. O'Neill, R. Baldick, U. Helman, M. Rothkopf, and W. Stewart, Jr, "Dispatchble transmission in RTO markets," IEEE Trans. Power Syst., vol. 20, no. 1, pp. 171-179, Feb. 2005.

[5] H.-P. Chao, S. Peck, S. Oren, and R. Wilson, "Flow-Based transmission rights and congestion management," Electricity J., vol. 13, no. 8, pp. 38-58, Oct. 2000.

[6] ESAI's proposal to accelerate merchant AC transmission investment ESAI, 2003, ESAI Occasional Memo.

[7] H. A. Gil and E. L. da Silva, "Modeling competition in transmission expansion," IEEE Trans. Power Syst., vol. 17, no. 4, pp. 1043-1049, Nov. 2002.

[8] P. Cramton and S. Stoft, "A capacity market that makes sense," in Proc. IEEE Power Eng. Soc. Gen. Meeting, 2005., Jun. 2005, pp. 3022-3034.

[9] B. J. Gail, J. G Farr, and S. F. Tierney, "The political economy of longterm generation adequacy: Why an ICAP mechanism is needed as part of standard market design," Electricity J., vol. 15, no. 7, pp. 53-62, Aug./Sep. 2002.

[10] A. S. Chuang, F. Wu, and P. Varaiya, "A game-theoretic model for generation expansion planning: Problem formulation and numerical comparisons," IEEE Trans. Power Syst., vol. 16, no. 4, pp. 885-891, Nov. 2001.

[11] F. H. Murphy and Y. Smeers, Generation Capacity Expansion in Imperfectly Competitive Restructured Electricity Markets. Louvain, Belgium: Univ. Catholique de Louvain, 2002.

[12] A. Botterud, M. D. Ilic, and I. Wangensteen, "Optimal investments in power generation under centralized and decentralized decision making," IEEE Trans. Power Syst., vol. 20, no. 1, pp. 254-263, Feb. 2005.

[13] E. Gnansounou, J. Dong, S. Pierre, and A. Quintero, "Market oriented planning of power generation expansion using agent-based model," in Proc. Power Syst. Conf. Expo., 2004., Oct. 10-13, 2004, vol. 3, pp. 1306-1311.

[14] S. McCusker, B. Hobbs, and Y. Ji, "Distributed utility planning using probabilistic production costing and generalized benders decomposition," IEEE Trans. Power Syst., vol. 17, no. 2, pp. 497-505, May 2002.

[15] S. Binato, M. V. F. Pereira, and S. Granville, "A new benders decomposition approach to solve power transmission network design problems," IEEE Trans. Power Syst., vol. 16, no. 2, pp. 235-240, May 2001.

[16] E. Sauma and S. Oren, "Proactive planning and valuation of transmission investments in restructured electricity markets," J. Regul. Econ., vol. 30, pp. 261-290, Sep. 2006.

[17] M. Shahidehpour and Y. Fu, "Applying benders decomposition to power systems," IEEE Power Energy Mag., vol. 3, no. 2, pp. 20-21, Mar.-Apr. 2005.

[18] A. Conejo, E. Castillo, R. Minguez, and R. Garcia-Bertrand, Decomposition Techniques in Mathematical Programming. New York: Springer, 2006.

[19] M. Shahidehpour and M. Marwali, Maintenance Scheduling in Restructured Power Systems. Norwell, MA: Kluwer, 2000.

[20] M. V. F. Pereira, L. M. V. G. Pinto, S. H. F. Cunha, and G. C. Oliveira, "A decomposition approach to automated generation/transmission expansion planning," IEEE Trans. Power App. Syst., vol. PAS-5, no. 11, pp. 3074-3083, 1985.

[21] M. V. F. Pereira, L. M. V. G. Pinto, G. C. Oliveira, and S. H. F. Cunha, Composite generation-transmission expansion planning, 1987, Tech. Rep. EL-5179, EPRI. Project 2473-9. 
[22] J. H. Roh, M. Shahidehpour, and Y. Fu, "Security-Constrained resource planning in electricity markets," IEEE Trans. Power Syst., vol. 22, no. 2, pp. 812-820, May 2007.

[23] W. Wong, H. Chao, D. Julian, P. Lindberg, and S. Kolluri, "Transmission planning in a deregulated environment," in Proc. IEEE Transmission Distribution Conf., Apr. 1999, vol. 1, pp. 350-355.

[24] NEA/IEA, projected costs of generating electricity update 1998, Paris, France, 1998, OECD/IEA.

[25] Y. Fu, Z. Li, and M. Shahidehpour, "Profit-based generation resource planning," IMA J. Manage. Math., vol. 15, no. 4, pp. 273-289, Oct. 1, 2004.

[26] Standard market design and structure notice of proposed rule making, U.S. Federal Energy Regulatory Commission, 2002, 18 CFR Part 35, Docket Number RM01-12-000.

[27] Y. Fu, M. Shahidehpour, and Z. Li, "Long-term security-constrained unit commitment: Hybrid subgradient and Danzig-Wolfe decomposition," IEEE Trans. Power Syst., vol. 20, no. 4, pp. 2093-2106, Nov. 2005.

[28] Expansion planning for electrical generating systems, IAEA, Vienna, Austria, 1984.

[29] S. Boyd, L. Xiao, and A. Mutapcic, Subgradient methods, Stanford Univ., Stanford, CA, 2003, Notes for EE392o.

[30] A. Wood and B. Wollenberg, Power Generation, Operation and Control. New York: Wiley, 1996.

[31] E. Litvinov, T. Zheng, G. Rosenwald, and P. Shamsollahi, "Marginal loss modeling in LMP calculation," IEEE Trans. Power Syst., vol. 19, no. 2, pp. 880-888, May 2004.

[32] M. Shahidehpour, H. Yamin, and Z. Y. Li, Market Operations in Electric Power Systems. New York: Wiley, 2002.
[33] T. Wu, M. Rothleder, Z. Alaywan, and A. D. Papalexopoulos, "Pricing energy and ancillary services in integrated market systems by an optimal power flow," IEEE Trans. Power Syst., vol. 19, no. 1, pp. 339-347, Feb. 2004.

Jae Hyung Roh received the B.S. degree in nuclear engineering from Seoul National University, Seoul, Korea, in 1993 and the M.S. degree in electrical engineering from Hongik University, Korea, in 2002. He is pursuing the Ph.D. degree at the Illinois Institute of Technology, Chicago.

$\mathrm{He}$ is the Deputy Manager in the Power Planning Department, Korea Power Exchange, Korea.

Mohammad Shahidehpour (F'01) is Carl Bodine Distinguished Professor and Chairman in the Electrical and Computer Engineering Department, Illinois Institute of Technology, Chicago.

Dr. Shahidehpour is the recipient of the 2005 IEEE/PES Prize Paper Award.

Yong Fu (M'05) received the B.S. and M.S. degrees in electrical engineering from Shanghai Jiaotong University, China, in 1997 and 2002, respectively, and the $\mathrm{Ph} . \mathrm{D}$. degree in electrical engineering from the Illinois Institute of Technology, Chicago, in 2006.

Presently, he is a Senior Associate Researcher in the Electrical Power and Power Electronics Center at the Illinois Institute of Technology. 